\title{
Antioxidant Activity of Fractions from Garcinia hombroniana Pierre Leaves Extracts
}

\author{
Nita Triadisti ${ }^{12^{*}}$, Rani Sauriasari ${ }^{1}$, Berna Elya $^{1 *}$
}

\section{Nita Triadisti ${ }^{1,2^{*}}$ Rani Sauriasari ${ }^{1}$, Berna Elya ${ }^{1 *}$}

'Faculty of Pharmacy, Universitas Indonesia 16424, Depok, INDONESIA.

${ }^{2}$ Faculty of Pharmacy, Universitas Muhammadiyah Banjarmasin, 70114, Banjarmasin, INDONESIA.

\section{Correspondence}

Nita Triadisti

Faculty of Pharmacy, Universitas Muhammadiyah Banjarmasin, 70114, Banjarmasin, INDONESIA.

Phone no : +6287814381488

E-mail: triadisti@gmail.com

\section{Berna Elya}

Faculty of Pharmacy, Universitas Indonesia, 16424, Depok, INDONESIA.

Phone no : +6281314161497

History

- Submission Date: 12-01-2018

- Review completed: 14-02-2018

- Accepted Date: 03-05-2018

DOI : 10.5530/pj.2018.4.112

Article Available online

http://www.phcogi.com/v10/i4

\section{Copyright}

(c) 2018 Phcog.Net. This is an openaccess article distributed under the terms of the Creative Commons Attribution 4.0 International license.

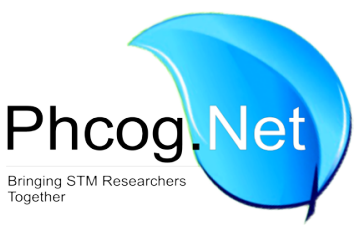

\begin{abstract}
Introduction: Radicals were compounds that generated in normal metabolism and create cell damage. A significant increase of free radical and decreased radical elimination can lead to oxidative stress. Oxidative stress plays an important role in the development of many diseases. Enhanced supply of antioxidants will help prevent the morbidity of many diseases. Garcinia hombroniana Pierre has potency as an antioxidant, but study to evaluate the active fractions as an antioxidant has not been done. Objective: The objective of the study was to evaluate antioxidant activity of fractions separated from ethyl acetate (EtOAc) and methanol $(\mathrm{MeOH})$ extract of Garcinia hombroniana leaves and to obtain active fractions to facilitate finding a pure antioxidant compound. Methods: The extract was fractionated using column chromatography, while antioxidant activity assay was conducted in vitro using spectrophotometric methods with DPPH and FRAP method. Results: EtOAc extract of $G$. hombroniana leaves yielded EA-8 with radical scavenging percentage $32.67 \%$ (10 ppm, with DPPH method) and EA-11 with antioxidant activity percentage $25.73 \%$ (10 ppm, with FRAP method) as the most active fraction from EtOAc extract, while $\mathrm{MeOH}$ extract yielded $\mathrm{M}-3$ with radical scavenging percentage $37.42 \%$ (10 ppm, with DPPH method) and $26.70 \%$ (10 ppm, with FRAP method) as the most active fraction from $\mathrm{MeOH}$ extract Conclusion: Most active fractions has good antioxidant activity, worthy for further study to isolate antioxidant compound which is responsible for antioxidant activity. However, the percentage of radical scavenging or antioxidant activity of all active fractions were smaller than quercetin as a positive control.

Key words: Column chromatography, Free radicals, Spectrophotometric thin layer chromatography.
\end{abstract}

\section{INTRODUCTION}

A balance between the rate of free radical production and its elimination is very important. Excessive free radical production can be harmful to the body. Radicals were compounds with free electrons that generated in normal metabolism and create cell damage thus have an adverse effect on the cellular metabolism. ${ }^{1}$ A Significant increase of free radical and decreased radical elimination of cells can lead to oxidative stress. Oxidative stress plays an important role in the development of vascular complications in type 2 diabetes, the aging process, cancer and many diseases. ${ }^{2,3}$ Antioxidants can inhibit the formation of free radicals, reduce free radicals, and increase the defense of enzymatic antioxidants. Enhanced supply of antioxidants will help prevent the morbidity of many diseases. ${ }^{4}$

The antioxidant compounds in many plants perform as a radical scavenger and could converting radicals into low-reactivity compound. ${ }^{5}$ Indonesia has a lot of plants potentially to be prepared as an antioxidant agent. One of the genus in Clusiacease family is Garcinia, which native to regions of Northeast Australia, Asia, Southern Africa and West Polynesia. ${ }^{6}$ Many species of Garcinia have been studied for their activity and phytochemical content and among many species of Garcinia, the scientific data of Garcinia hombroniana is still rare compared to other Garcinia species.

The earlier studies show the leaves of $G$. hombroniana contain tannins, terpenoids, alkaloids, phenols, flavonoids, and saponins. ${ }^{7,8}$ Previous studies have demonstrated the antioxidant activity of ethyl acetate (EtOAc) and methanol $(\mathrm{MeOH})$ extract from the leaves of $G$. hombroniana, ${ }^{9}$ but study to obtain the active fraction as an antioxidant has not been done. The objective of the study was to evaluate antioxidant activity of fractions separated from EtOAc and $\mathrm{MeOH}$ extract of $G$. hombroniana leaves and to obtain active fractions to facilitate finding a pure antioxidant compound.

\section{MATERIALS AND METHODS}

\section{Materials}

EtOAc and $\mathrm{MeOH}$ extract from G. hombroniana Pierre leaves which extracted by maceration were obtained from Laboratory of Phytochemistry and Pharmacognosy, Faculty of Pharmacy, University of Indonesia. The leaves of G. hombro-

Cite this article: Triadisti N, Sauriasari R, Elya B. Antioxidant Activity of Fractions from Garcinia hombroniana Pierre Leaves Extracts. Pharmacog J. 2018;10(4):682-5. 
niana were identified by Dr. Joeni Setijo Rahajoe, collected in Bogor, Indonesia. A voucher specimen has been saved in Laboratory of Phytochemistry and Pharmacognosy, Faculty of Pharmacy, Universitas Indonesia. Analytical grade ethyl acetate (EtOAc), n-hexane, and methanol $(\mathrm{MeOH})$, technical grade n-hexanex, EtOAc, and $\mathrm{MeOH}$ which have been distilled, silica gel 70-230 mesh (Merck), Thin Layer Chromatography Plate (Merck). Quercetin (Sigma Aldrich, India), DPPH (1, 1-diphenyl2-picrylhydrazyl) (Sigma-Aldrich, Germany), TPTZ (2,4,6-tripyridyl-striazine) (Sigma Aldrich, Switzerland), $\mathrm{FeCl} 3, \mathrm{HCl}$, sodium acetate, and acetic acid (glacial) (Merck, Germany) were used.

\section{Fractions Pooling using Column Chromatography and Analytical Thin Layer Chromatography (TLC)}

EtOAc and $\mathrm{MeOH}$ extracts of $\mathrm{G}$. hombroniana leaves were fractionated by column chromatography with wet packing method. Silica gel 70-230 mesh used as the stationary phase while the mobile phase used a mix of solvents (EtOAc, n- $\mathrm{Hx}$, and $\mathrm{MeOH}$ ) with increasing polarity. Solvent gradient system was used in elution process. Thin layer chromatography is used to identify fractions with the same chromatogram pattern. The fraction with similar chromatogram pattern then merged and checked its antioxidant with DPPH and FRAP method.

\section{Antioxidant Activity Assay \\ DPPH Method}

The antioxidant activity test method is a DPPH free radical scavenging method adopted from Bobo-García et al with slight modification. ${ }^{10}$ The sample solution was piped $20 \mu \mathrm{L}$ and inserted into the microplate well. Each solution was added $180 \mu \mathrm{L}$ of $150 \mu \mathrm{mol} / \mathrm{L}$ DPPH solution. The control solution consisted of $20 \mu \mathrm{L}$ methanol and $180 \mu \mathrm{L} \mathrm{DPPH}$ solution of $150 \mu \mathrm{mol} / \mathrm{L}$, while the blank solution consisted of $200 \mu \mathrm{L}$ methanol pro analysis. The solution is shaken for $60 \mathrm{sec}$ and then incubated at room temperature in the dark room for $40 \mathrm{~min}$. Absorbance was measured at $516 \mathrm{~nm}$ in the microplate reader (VersaMax). The percent DPPH scavenging was calculated using:

$$
\text { \# DPPH Scavenging }=\left[1-\frac{\mathrm{A}_{\text {sample }}-\mathrm{A}_{\text {blank }}}{\mathrm{A}_{\text {control }}-\mathrm{A}_{\text {blank }}}\right] \times 100
$$

\section{FRAP Method}

The antioxidant activity test using FRAP reagent, with the procedure adopted from Pereira in vitro with slight modification. ${ }^{11}$ The sample solution was piped $30 \mu \mathrm{L}$, inserted into a microplate well, followed by additional of $270 \mu \mathrm{L}$ FRAP reagent, then incubated and the absorbance was measured. A mixture of $30 \mu \mathrm{L}$ methanol and $270 \mu \mathrm{L}$ FRAP reagents was used as blank.

The percent antioxidant activity was calculated using:

$$
\% \text { Antioxidant Activity }=\left[\mathrm{A}_{\text {sample }}-\mathrm{A}_{\text {blank }}\right] \times 100
$$

\section{RESULTS AND DISCUSSION}

This study was performed to evaluate antioxidant activity of fractions separated from EtOAc and $\mathrm{MeOH}$ extract of G.hombroniana leaves. EtOAc extract yielded 14 fractions from its fractionation, while $\mathrm{MeOH}$ extract yielded 12 fractions (Table 1 and 2). Fractions were evaluated its antioxidant activity using microplate reader (VersaMax). in vitro studies of fractions demonstrated that all samples have antioxidant activity. All EtOAc fractions and $\mathrm{MeOH}$ fractions were tested for their antioxidant activity by DPPH and FRAP method. The test concentration of all fractions used in this test was $10 \mathrm{ppm}$.

\section{Table 1: Fractions from EtOAc extract.}

\begin{tabular}{cc}
\hline Fraction & Eluent of column \\
\hline EA-1 & $n-H x / E t O A c=9: 1$ \\
EA-2 & $n-H x / E t O A c=8: 2$ \\
EA-3 & $n-H x /$ EtOAc $=8: 2$ \\
EA-4 & $n-H x /$ EtOAc $=8: 2-7: 3$ \\
EA-5 & $n-H x /$ EtOAc $=7: 3$ \\
EA-6 & $n-H x /$ EtOAc $=7: 3-6: 4$ \\
EA-7 & $n-H x / E t O A c=5: 5$ \\
EA-8 & $n-H x /$ EtOAc $=4: 6-3: 7$ \\
EA-9 & $n-H x / E t O A c=2: 8-$ EtOAc/MeOH $=9: 1$ \\
EA-10 & EtOAc/MeOH $=9: 1-8: 2$ \\
EA-11 & EtOAc/MeOH $=7: 3$ \\
EA-12 & EtOAc/MeOH $=6: 4-2: 8$ \\
EA-13 & EtOAc/MeOH $=2: 8-0: 10$ \\
EA-14 & $n$
\end{tabular}

Description: $\mathrm{EA}=$ fraction from EtOAc extract, $\mathrm{n}-\mathrm{Hx}=\mathrm{n}-\mathrm{Hexane}$, EtOAc $=$ ethyl acetate, $\mathrm{MeOH}=$ methanol.

Table 2: Fractions from MeOH extract.

\begin{tabular}{cc}
\hline Fraction & Eluent of column \\
M-1 & $n-H x /$ EtOAc $=8: 2$ \\
M-2 & $n-H x / E t O A c=7: 3-2: 8$ \\
M-3 & $n-H x /$ EtOAc $=2: 8-$ EtOAc/MeOH $=9: 1$ \\
M-4 & EtOAc/MeOH $=9: 1-8: 2$ \\
M-5 & EtOAc/MeOH $=7: 3$ \\
M-6 & EtOAc/MeOH $=6: 4-5: 5$ \\
M-7 & EtOAc/MeOH $=5: 5-3: 7$ \\
M-8 & EtOAc/MeOH $=2: 8-5: 5$ \\
M-9 & EtOAc $/ \mathrm{MeOH}=4: 6$ \\
M-10 & EtOAc/MeOH $=0: 10$ \\
M-11 & EtOAc/MeOH $=0: 10$ \\
M-12 & EtOAc/MeOH $=0: 10$ \\
\hline
\end{tabular}

Description: $\mathrm{M}=$ fraction from $\mathrm{MeOH}$ extract, $\mathrm{n}-\mathrm{Hx}=\mathrm{n}-\mathrm{Hexane}$, EtOAc $=$ ethyl acetate, $\mathrm{MeOH}=$ methanol.

The antioxidant activity test results with DPPH method can be seen in Table 3 and 4, showed that the eighth fraction of EtOAc extract (EA-8) was the most active fraction as antioxidant compared with other EtOAc fractions, while the third fraction of $\mathrm{MeOH}$ extract (M-3) showed the highest activity as antioxidant compared with other $\mathrm{MeOH}$ fractions. Based on the antioxidant test using DPPH method, it can be seen that potential antioxidant activity between M-3 and EA-8 not much different. The antioxidant activity test results with FRAP method can be seen in Table 5 and 6 , showed that EA-11 is the fraction with the best antioxidant activity compared to other EtOAc fraction, whereas EA- 8 has the second best antioxidant activity. M-3 is the fraction with the best antioxidant activity compared to other $\mathrm{MeOH}$ fractions. The highest percentage of antioxidant activity was demonstrated by M-3. Antioxidant activity of active fractions may be due to the content of its electron donor compounds, hydrogen donor compounds or the possibility of synergistic effects among the compounds so as to provide antioxidant activity. ${ }^{12,13}$ Phyto- 
Table 3: Antioxidant Activity of Fractions from EtOAc extract by DPPH method.

\begin{tabular}{cc}
\hline Fraction & Percent Inhibition $(\%) \pm$ SD \\
\hline EA-1 & $19.34 \% \pm 0.67$ \\
EA-2 & $17.19 \% \pm 0.19$ \\
EA-3 & $18.90 \% \pm 0.29$ \\
EA-4 & $18.69 \% \pm 0.25$ \\
EA-5 & $17.97 \% \pm 0.51$ \\
EA-6 & $21.72 \% \pm 0.16$ \\
EA-7 & $23.11 \% \pm 0.67$ \\
EA-8 & $32.67 \% \pm 1.09$ \\
EA-9 & $25.65 \% \pm 0.58$ \\
EA-10 & $32.61 \% \pm 2.44$ \\
EA-11 & $32.28 \% \pm 1.43$ \\
EA-12 & $31.29 \% \pm 1.92$ \\
EA-13 & $23.55 \% \pm 0.16$ \\
EA-14 & $18.74 \% \pm 0.29$ \\
\hline
\end{tabular}

Data are mean $\pm \mathrm{SD}$ or $\% \pm \mathrm{SD}$ for triplicate measurements.

Table 4: Antioxidant Activity of Fractions from MeOH Extract by DPPH method.

\begin{tabular}{cc}
\hline Fraction & Percent Inhibition (\%) \pm SD \\
\hline M-1 & $32.76 \% \pm 0.25$ \\
M-2 & $17.97 \% \pm 0.19$ \\
M-3 & $37.42 \% \pm 0.67$ \\
M-4 & $26.29 \% \pm 0.42$ \\
M-5 & $22.44 \% \pm 0.92$ \\
M-6 & $34.66 \% \pm 0.57$ \\
M-7 & $18.13 \% \pm 1.59$ \\
M-8 & $18.19 \% \pm 0.58$ \\
M-9 & $19.02 \% \pm 1.10$ \\
M-10 & $20.01 \% \pm 0.79$ \\
M-11 & $25.54 \% \pm 0.57$ \\
M-12 & $19.79 \% \pm 0.19$ \\
\hline
\end{tabular}

Data are mean $\pm \mathrm{SD}$ or $\% \pm \mathrm{SD}$ for triplicate measurements.

constituents belonging to Garcinia hombroniana leaves, such as flavonoid may play a role in antioxidant activity. Flavonoids have antioxidant property, caused by the main structure such catechol structure, double bonds, and hydroxyl groups. Capability of flavonoid to chelate free radicals by donating electron or hydrogen atoms indicates its activity as a powerful antioxidant. ${ }^{14}$

The standard used in the antioxidant activity test is quercetin. Antioxidant activity of quercetin using DPPH showed that radical scavenging percentage of quercetin in $10 \mathrm{ppm}$ is $99.17 \%$ while using FRAP reagent showed that antioxidant activity percentage of quercetin in $10 \mathrm{ppm}$ is $63.90 \%$ (Table 7). Quercetin, used as a positive or comparative standard in antioxidant activity trials, showed better antioxidant activity compared with all active fractions. The antioxidant activity of quercetin is due to the presence of hydroxyl groups, double bonds, carbonyl groups and
Table 5: Antioxidant Activity of Fractions from EtOAc extract (FRAP method).

\begin{tabular}{cc}
\hline Fraction & Percent Inhibition (\%) \pm SD \\
\hline EA-1 & $10.40 \% \pm 0.52$ \\
EA-2 & $5.70 \% \pm 1.28$ \\
EA-3 & $6.30 \% \pm 0.72$ \\
EA-4 & $6.20 \% \pm 0.62$ \\
EA-5 & $4.00 \% \pm 0.58$ \\
EA-6 & $7.77 \% \pm 0.46$ \\
EA-7 & $8.10 \% \pm 0.26$ \\
EA-8 & $22.37 \% \pm 0.67$ \\
EA-9 & $15.20 \% \pm 3.85$ \\
EA-10 & $22.10 \% \pm 1.13$ \\
EA-11 & $25.73 \% \pm 1.99$ \\
EA-12 & $18.90 \% \pm 1.68$ \\
EA-13 & $9.60 \% \pm 0.26$ \\
EA-14 & $3.80 \% \pm 0.35$ \\
\hline
\end{tabular}

Data are mean $\pm \mathrm{SD}$ or $\% \pm \mathrm{SD}$ for triplicate measurements.

Table 6: Antioxidant Activity of Fractions from MeOH Extract (FRAP method).

\begin{tabular}{cc}
\hline Fraction & Percent Inhibition $(\%) \pm$ SD \\
\hline M-1 & $4.400 \% \pm 1.000$ \\
M-2 & $6.070 \% \pm 0.321$ \\
M-3 & $26.700 \% \pm 1.136$ \\
M-4 & $16.100 \% \pm 0.436$ \\
M-5 & $7.90 \% \pm 0.30$ \\
M-6 & $23.03 \% \pm 1.10$ \\
M-7 & $3.07 \% \pm 0.06$ \\
M-8 & $2.53 \% \pm 0.35$ \\
M-9 & $2.13 \% \pm 0.32$ \\
M-10 & $3.77 \% \pm 0.42$ \\
M-11 & $10.67 \% \pm 0.55$ \\
M-12 & $4.30 \% \pm 0.36$ \\
\hline
\end{tabular}

Data are mean \pm SD or $\% \pm$ SD for triplicate measurements

Table 7: Antioxidant Activity of Quercetin (10 $\mu \mathrm{g} / \mathrm{mL})$.

\begin{tabular}{cc}
\hline Method & Percent Inhibition (\%) \pm SD \\
\hline DPPH & $99.17 \pm 0.70$ \\
FRAP & $63.90 \pm 0.60$ \\
\hline
\end{tabular}

Data are mean $\pm \mathrm{SD}$ or $\% \pm \mathrm{SD}$ for triplicate measurements

aromatic rings with hydroxyl groups, which play a role in its ability as an antioxidant. ${ }^{15}$

\section{CONCLUSION}

The test result showed that most active fraction from the crude EtOAc extract are EA-8 with radical scavenging percentage 32.67\% (10 ppm, DPPH method) and EA-11 with antioxidant activity percentage $25.73 \%$ (10 ppm, FRAP method), while most active fraction from the crude $\mathrm{MeOH}$ extract is $\mathrm{M}-3$ with radical scavenging percentage $37.42 \%$ 
(10 ppm, DPPH method) and antioxidant activity percentage $26.70 \%$ (10 ppm, FRAP method). The percentage of radical scavenging or antioxidant activity of all active fractions were smaller than quercetin as a positive control. Most active fractions have good antioxidant activity, worthy for further study to isolate antioxidant compound which is responsible for antioxidant activity.

\section{ACKNOWLEDGEMENT}

This study was partly funded by PITTA Grant, Directorate of Research and Community Engagement, Universitas Indonesia.

\section{CONFLICT OF INTEREST}

The authors have no conflict of interest to declare.

\section{ABBREVIATIONS}

TLC: Thin Layer Chromatography; DPPH: 1, 1-diphenyl-2picrylhydrazyl; FRAP: Ferric Reducing Antioxidant Power; TPTZ: 2,4,6-tripyridyl-s-triazine.

\section{REFERENCES}

1. Vermerris W, Nicholson R. Phenolic Compound Biochemistry. Dordrecht: Springer. 2006.

2. Ullah A, Khan A, Khan I. Diabetes mellitus and oxidative stress: A concise review. Saudi Pharm J. 2016;24(5):547-53.
3. Sanvicens N, Go V, Messeguer A, Cotter TG. The radical scavenger CR-6 protects SH-SY5Y neuroblastoma cells from oxidative stress-induced apoptosis: effect on survival pathways. J Neurochem. 2006;98(3):735-47.

4. Bajaj S, Khan A. Antioxidants and Diabetes. Indian J Endocrinol Metab. 2016;16(suppl 2):S261-S71.

5. Mandal S, Yadav S, Yadav S, Nema RK. Antioxidants: A Review. J Chem Pharm Res. 2009;1(1):102-4.

6. Nargis J, Melati K, Lai C, et al. activities of the bark extracts of Garcinia hombroniana. African J Pharm Pharmacol. 2013;7(8):454-9.

7. Dyary $H$, Arifah A, Sharma R, et al. Antitrypanosomal screening and cytotoxic effects of selected medicinal plants. Trop Biomed. 2014;31(1):89-96.

8. Elya B, Basah K, Mun'Im A, Yuliastuti W, Bangun A, Septiana EK. Screening of $\alpha$-glucosidase inhibitory activity from some plants of Apocynaceae, Clusiaceae, Euphorbiaceae, and Rubiaceae. J Biomed Biotechnol. 2012;2012(281078):1-6.

9. Marlin S, Elya B. Antioxidant Activity and Lipoxygenase Enzyme Inhibition Assay with Total Flavonoid Content from Garcinia hombroniana Pierre Leaves. Pharmacogn J. 2017;9(2):267-72

10. Bobo-garcía G, Davidov-pardo G, Arroqui C, Marín-arroyo MR. Intra-laboratory validation of microplate methods for total phenolic content and antioxidant activity on polyphenolic extracts, and comparison with conventional spectrophotometric methods. J Sci Food Agric. 2014;95(1):204-9.

11. Pereira A, Lenz D, Nogueira BV, et al. Gastroprotective activity of the resin from Virola oleifera. Pharm Biol. 2017;55(1):472-80

12. Lee CY, Nanah C, Held R, et al. HHS Public Access. Biochimie. 2016;111:125-34.

13. Velika B, Kron I. Antioxidant properties of benzoic acid derivatives against Superoxide radical. Free Radicals Antioxidants. 2012;2(4):62-7.

14. Bou I, Wilhelmov N, Academy TC. Antioxidant and prooxidant properties of flavonoids. Fitoterapia. 2011;82(4):513-23.

15. Ozgen S, Kilinc OK, Selamoglu Z. Turkish Journal of Agriculture - Food Science and Technology Antioxidant Activity of Quercetin: A Mechanistic Review. Turkish J Agric - Food Sci Technol. 2016;4(12):1134-8.

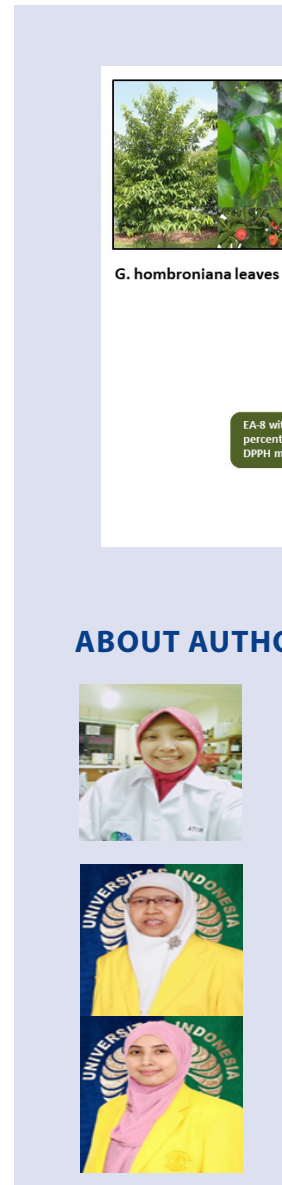

GRAPHICAL ABSTRACT

Ethyl acetate fractions Methanol fractions

\section{(1)}

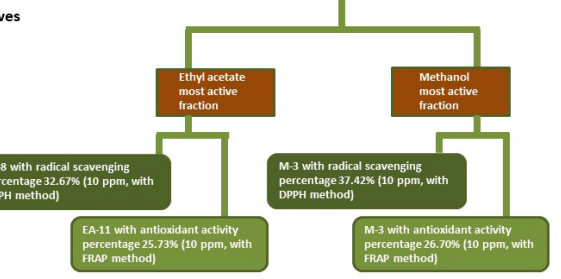

\section{SUMMARY}

- Fractionation of G.hombroniana leaves extract was conducted using column chromatography.

- Antioxidant activity assay of fractions was conducted in vitro using spectrophotometric methods with DPPH and FRAP method.

- Ethyl acetate extract of $G$. hombroniana leaves yielded EA-8 with radical scavenging percentage $32.67 \%$ (10 ppm, with DPPH method) and EA-11 with antioxidant activity percentage $25.73 \%$ (10 ppm, with FRAP method) as the most active fraction.

- Methanol extract yielded M-3 with radical scavenging percentage $37.42 \%$ (10 ppm, with DPPH method) and $26.70 \%$ (10 ppm, with FRAP method) as the most active fraction.

Cite this article: Triadisti N, Sauriasari R, Elya B. Antioxidant Activity of Fractions from Garcinia hombroniana Pierre Leaves Extracts. Pharmacog J. 2018;10(4):682-5. 